\title{
Comparative Study of Thermophysical Parameters of Different Types of Upholstery Wood and the Influence of Density on Combustion Parameters at Microscale
}

\author{
Abdoul Fayçal Baguian', Salifou Koucka Ouiminga1*, Sampawinde Augustin Zongo1, \\ Ibrahim Harouna Gado ${ }^{2}$
}

${ }^{1}$ LPCE, Département de Physique, Université Joseph Ki-Zerbo, Ouagadougou, Burkina Faso

${ }^{2}$ Département de Physique, Faculté des Sciences et Techniques, Université Dan Dicko

Dankoulodo de Maradi, Maradi, Niger

Email: *salif0477@yahoo.com

How to cite this paper: Baguian, A.F., Ouiminga, S.K., Zongo, S.A. and Gado, I.H. (2022) Comparative Study of Thermophysical Parameters of Different Types of Upholstery Wood and the Influence of Density on Combustion Parameters at Microscale. Open Journal of Safety Science and Technology, 12, 1-16.

https://doi.org/10.4236/ojsst.2022.121001

Received: September 9, 2021

Accepted: January 10, 2022

Published: January 13, 2022

Copyright () 2022 by author(s) and Scientific Research Publishing Inc. This work is licensed under the Creative Commons Attribution International License (CC BY 4.0).

http://creativecommons.org/licenses/by/4.0/

\begin{abstract}
The fire behaviour of five types of wood was studied on a microscale. Some thermophysical parameters such as thermal conductivity, effusivity and diffusivity were also evaluated. The microscale analysis is based on the analysis of several parameters such as the assessment of heat released rates (HRR), peak heat released rates (pHRR), total heat released (THR), enthalpy variation $(\triangle \mathrm{h})$ and residue rates with the combustion microcalorimeter (PCFC). The PF2C device was used to measure the conductivity, effusivity and diffusivity of wood, while the PCFC for the microscale study of wood behaviour in combustive situations. In terms of thermal conductivity, wood conducts heat with difficulty, while the other types, namely frake, bete, tek and red wood, more easily conduct heat and therefore cannot be considered as thermal insulators. For results, in terms of measuring effusivity, white wood has the smallest value, which means that it exchanges less thermal energy with its environment. Red and tek woods exchange much more energy with the environment compared to other types of wood. We observe that tek wood has the highest diffusivity, which means that it is the wood that reacts as quickly as possible to the change in temperature. White and frake woods have the same value of thermal diffusivity as red and bete wood which have the lowest thermal diffusivities. The fire behaviour of these materials is a very little variable on the microscale and we can conclude that at this level there is no major difference for our different types of wood. Hence, there is no influence of density on the microscale. We can say that for the white and tek wood the
\end{abstract}


complete combustion begins at $700^{\circ} \mathrm{C}$. By this same method of analysis, we come to the conclusion that the frake, bete and red woods tend towards a complete combustion at $675^{\circ} \mathrm{C}$. At $675^{\circ} \mathrm{C}$ the bete and frake woods have the best combustive yields, to a lesser extent than the red and tek woods. The bete wood has the highest activation energy and the white wood the lowest.

\section{Keywords}

Fire Behaviour, Material Scale, Thermophysical Parameters

\section{Introduction}

The mechanical properties of wood, its price and lightness make it a very attractive material for several uses. The first and best known around the world is its use in the construction of furniture and tools of various sizes and properties intended, among other things, to furnish domestic habitats. In addition, the ease of transformation it offers makes it easy to format increasingly complex designs. The morphology and chemical composition of material are responsible for macroscopic properties such as conductivity, effusivity, diffusivity, etc... In terms of fire safety in domestic habitats, it is important or even crucial to know the fire behaviour of the furniture that is how long these materials have a strong influence on the speed of flames spread during fires. For our part, emphasis is placed on the study of the fire behaviour of the five types of wood most used for furniture in West Africa, namely red wood, bete wood, tek wood, frake wood and white wood. The fire behaviour of materials depends on the chemical processes that occur during their thermal degradation. However, the difficulties encountered concern the lack of data, which seriously hampers a better understanding of the phenomena observed during fires in domestic habitats: non-existent, incomplete or imprecise data [1] [2]. The tests for the standardization and classification of materials used in Africa and Burkina Faso in particular, are in many cases inadequate to determine with relevance the behavior of materials in the event of fire. They must therefore evolve in the light of new scientific investigations. The description of the combustion of complex materials, such as those commonly used in housing and furnishings, is based on a large number of simplifications (assumptions) leading to inaccurate and inadequate results in numerical modelling [3]. It is notable that in the field of transport, where the materials present are mastered, numerical simulations lead to results that are much more faithful to reality [4]. Thus, using the experimental device of "Pyrolysis-Combustion Flow Calorimetry" (PCFC), we decided to make a comparative study of thermophysical parameters of different wood types and the influence of density on combustion parameters at the microscale. This study will enrich the database of fire behaviour of five types of wood and check whether there is an influence of the density of each type of wood on thermophysical parameters such as the maximum heat flow (pHRR), the temperature of the maximum heat 
flow (TpHRR), the total heat released (THR), the residue rate after combustion and the amount of heat involved in a thermomechanical transformation, i.e. enthalpy. In the study of wood degradation, different experimental techniques have been described. They generally consist of monitoring the mass and/or emission of volatile products of degradation as a function of temperature. In this case, PCFC is one of the techniques of choice in the study of biomass degradation because it makes it possible to assess the fire behaviour at the microscale of the materials studied.

\section{Materials and Methods}

Five types of wood commonly called white wood, red wood, frake wood, tek wood and bete wood are considered in our study. They are all commonly used in furniture and the construction of domestic habitats in West Africa. The woods were obtained on the market in Burkina Faso and do not contain flame retardants (Figure 1).

The physical and some mechanical characteristics of the woods studied are presented in Table 1 [5].

Table 1. Physical and mechanical characteristics of the five types of wood studied.

\begin{tabular}{|c|c|c|c|c|c|c|c|c|c|c|c|c|c|c|c|c|}
\hline \multicolumn{9}{|c|}{ Physical characteristics } & \multicolumn{8}{|c|}{ Mechanical characteristics } \\
\hline \multirow[t]{3}{*}{$\begin{array}{l}\text { Types of } \\
\text { woods }\end{array}$} & \multirow{3}{*}{ 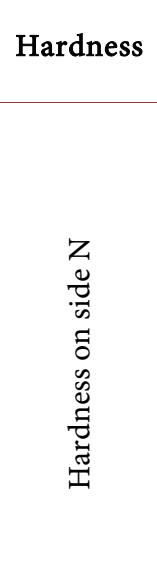 } & \multicolumn{2}{|c|}{$\begin{array}{l}\text { Specific } \\
\text { weights }\end{array}$} & \multicolumn{5}{|c|}{ Retractibility } & \multicolumn{3}{|c|}{$\begin{array}{c}\text { Transversal } \\
\text { cohesion }\end{array}$} & \multicolumn{5}{|c|}{ Axial cohesion } \\
\hline & & \multirow[b]{2}{*}{ 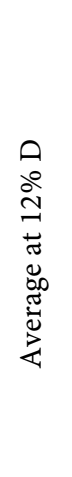 } & \multirow[b]{2}{*}{ 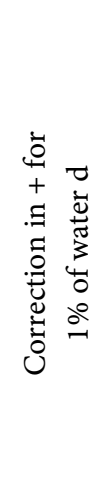 } & \multirow{2}{*}{ 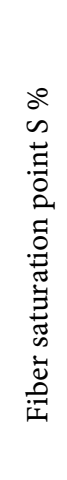 } & \multirow[b]{2}{*}{$\begin{array}{l}0 \\
0 \\
0 \\
\Xi \\
\Xi \\
0 \\
0 \\
0 \\
0 \\
0 \\
0\end{array}$} & \multirow{2}{*}{ 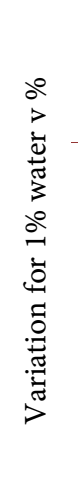 } & \multicolumn{2}{|c|}{$\begin{array}{l}\text { Total } \\
\text { linear }\end{array}$} & \multicolumn{3}{|c|}{$\begin{array}{l}\text { Average } \\
\text { resistance }\end{array}$} & \multicolumn{2}{|c|}{$\begin{array}{c}\text { Compression } \\
\text { to } 12 \% \\
\text { humidity }\end{array}$} & \multicolumn{2}{|c|}{$\begin{array}{c}\text { Static bending } \\
\text { at } 12 \% \\
\text { humidity }\end{array}$} & \multirow{2}{*}{ 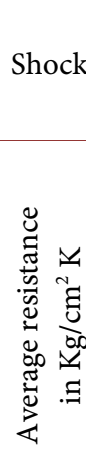 } \\
\hline & & & & & & & 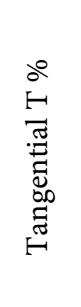 & 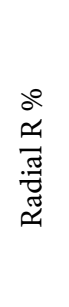 & 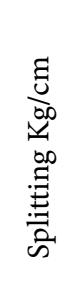 & 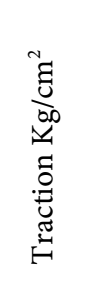 & 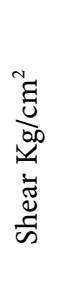 & 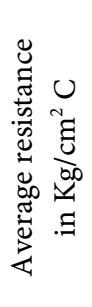 & 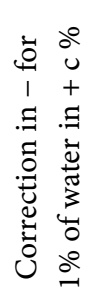 & 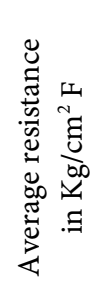 & 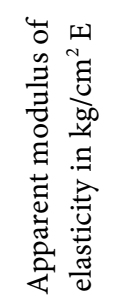 & \\
\hline $\begin{array}{l}\text { White } \\
\text { wood }\end{array}$ & 2.1 & 0.50 & 0.0030 & 37 & 14.4 & 0.40 & 11.3 & 5.0 & 16.0 & 20.2 & 82 & 368 & 7.1 & 1108 & 101000 & 0.30 \\
\hline $\begin{array}{l}\text { Frake } \\
\text { wood }\end{array}$ & 2.4 & 0.51 & 0.0031 & 36 & 11.1 & 0.32 & 6.7 & 4.4 & 13.1 & 23.3 & - & 462 & 6.3 & 1255 & 109000 & 0.21 \\
\hline $\begin{array}{l}\text { Bete } \\
\text { wood }\end{array}$ & 5.6 & 0.70 & 0.0042 & 30 & 11.3 & 0.38 & 8.4 & 5.4 & 16.5 & 26.6 & 96 & 697 & 3.7 & 1802 & 117000 & 0.61 \\
\hline $\begin{array}{c}\text { Tek } \\
\text { wood }\end{array}$ & 4.3 & 0.63 & 0.0050 & 26 & 6.6 & 0.26 & 3.4 & 2.6 & 20.4 & 28.7 & 62 & 452 & 2.8 & 1214 & 87000 & 0.23 \\
\hline $\begin{array}{c}\text { Red } \\
\text { wood }\end{array}$ & 8.1 & 0.88 & 0.0040 & 22 & 11.9 & 0.56 & 7.2 & 4.6 & 19.5 & 25.6 & 94 & 763 & 4.9 & 1780 & 140000 & 0.48 \\
\hline
\end{tabular}




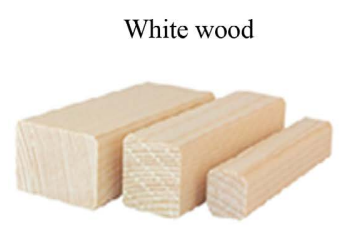

Tek wood

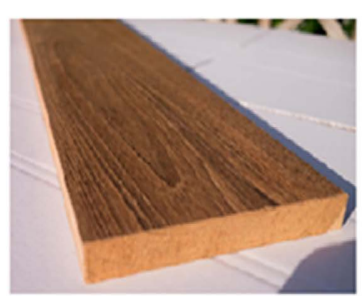

Frake wood

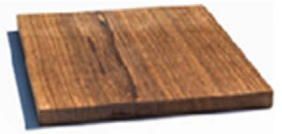

Red wood

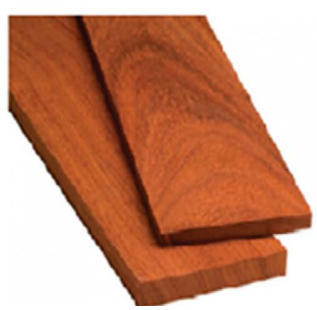

Figure 1. The five (5) types of wood studied.

The FP2C is a device consisting of a hot wire conductivimeter, a hot plane effusivimeter and a hot ring diffusivimeter. It has been used to measure the conductivity, effusivity and diffusivity of wood. This test was performed according to ASTM D5930-97 and RILEM AAC 11-3. For all types of wood, the samples are in square form $10 \mathrm{~cm}$ side and $5 \mathrm{~cm}$ thick. The hot wire technique is the classical transient method of measuring the thermal conductivity (Conductivity from 0.02 to $5 \mathrm{~W} \cdot \mathrm{m}^{-1} \cdot \mathrm{K}^{-1}$ ) of moderately conductive insulating materials. The device consists of a thermal shock probe, to be placed between two samples of the material to be characterized (symmetrical mounting) by an electronic acquisition box and software of graphical interface type to control the tests and process the results. The principle of the impact probe is to locally produce a low heating of the material (a few degrees above room temperature) and to measure this temperature rise over time (duration of a few minutes). By a mathematical processing of this signal integrated into the software provided, the identification of the thermal conductivity is carried out. This principle of probe and device was developed by the CSTB (Scientific and Technical Center of the Building). The hot wire conductivimeter can be supplemented with a hot plane probe for estimating thermal effusivity from 20 to $10,000 \mathrm{~J} \cdot \mathrm{m}^{-2} \cdot \mathrm{K}^{-1} \cdot \mathrm{s}^{-1 / 2}$ and a hot ring probe for estimating thermal diffusivity from 0.1 to $4 \mathrm{~mm}^{2} \cdot \mathrm{K}^{-1}$. Depending on the specifics of the materials to be characterized or the thermal properties to be searched, it is enough to connect the retained probe to the FP2C power supply and use the associated software (Figure 2).

The combustion microcalorimeter, also known as the Pyrolysis-Combustion Flow Calorimeter (PCFC), is a device developed to evaluate certain important parameters of the flammability of solid fuels by flameless combustion [6]. Its principle (in Figure 3) is based on the original concept of Susott and al. which relates to the separation in a fire of the processes taking place in the solid state and in the gaseous state, by the increasing heating of a few milligrams of product under an inert atmosphere [7]. The device we used is of the Fire Testing Technology (FTT) brand. Combustion microcalorimeter tests require only a few 


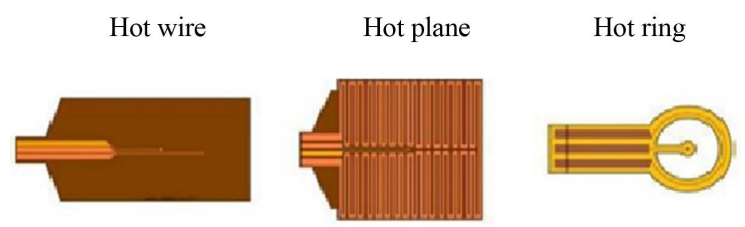

Figure 2. Hot wire conductivimeter-Hot plane probe-Hot ring diffusivimeter.

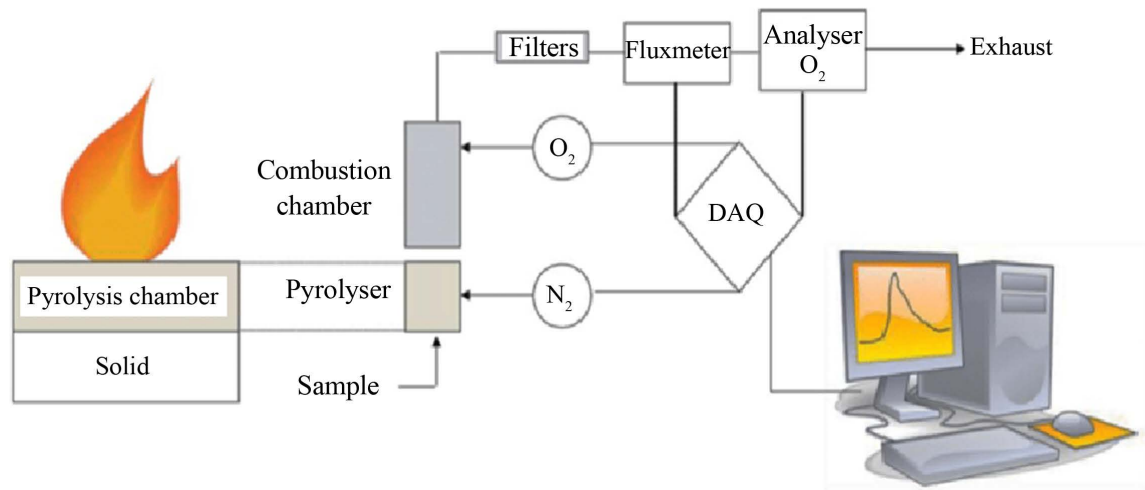

Figure 3. Illustration of the microcalorimeter experimental device (DAQ stands for data aquisition).

milligrams of samples, so they do not represent real fires. These tests provide a better understanding of the fire behaviour of solid materials. Other fire analysis devices such as the radiant cone and the calorimeter cone allow for more representative results on a real scale. The PCFC, on the other hand, makes it possible to evaluate samples at conditions of complete combustion. This allows the conditions (oxygen levels and temperature) in the PCFC combustion chamber to reduce the number of accidents (thermal stability problem) [8]. In this article, the combustion temperature in the PCFC has been varied in order to study the combustion efficiency (X), the activation energy (Ea) and the influence of the density of the samples on the combustion for the different woods that we encounter in the furnishings of the domestic habitat in West Africa. This work is done to better classify the fire behaviour of different materials in terms of fire safety.

\section{Results and Discussion}

During fires in domestic habitats furniture is one of the means by which the fire spreads more or less at high speed. It is therefore, necessary to know a certain number of characteristics concerning their behaviour in fire in order to anticipate in the means of preventing fires through numerical simulations.

In the fire behaviour of a solid material, the following are generally monitored:

- The diffusion of heat in an environment without macroscopic movement of matter. In other words, the surface thermal power transmitted per unit length of the material is subjected to a temperature difference;

- The ability of a material to exchange heat with its environment. Specifically, 
the sensitivity of the surface temperature of a material to a variation in the heat flow received by that surface;

- The thermal behaviour of a transient material which characterises its ability to transmit heat more or less quickly.

This is why we have been interested, for this work, in determining the thermal conductivity, effusivity and diffusivity of wood.

Indeed, the higher the thermal conductivity of a material, the more heat the material conducts, and the less insulating it is. Also, a very conductive and very capacitive material will have a surface temperature insensitive to variations in flow and will therefore be very effusive. And finally, the lower the thermal diffusivity, the longer it takes for the heat to pass through the material [9].

\subsection{Determination of Conductivity-Effusivity-Diffusivity Parameters}

\subsubsection{Thermal Conductivity}

The thermal conductivity values of the five wood types are shown in Figure 4.

It is observed that frake and bete woods have almost the same thermal conductivities, followed by red and tek woods which also have almost the same values. White wood has the lowest conductivity. The latter will hardly conduct the heat after [10]. On the other hand, the other types, namely frake, bete, tek and red wood, will conduct heat more easily and cannot therefore be considered as thermal insulators according to [11].

\subsubsection{Thermal Effusivity}

The results obtained for the determination of the thermal effusivity of the wood are presented in Figure 5.

We find that red and tek woods, frake and bete woods have the same values. White wood has the smallest value, which means that it exchanges less thermal energy with its environment. Red and tek woods exchange much more energy with the environment compared to other types of wood.

\section{Conductivity $(\mathrm{W} / \mathrm{m} / \mathrm{K})$}

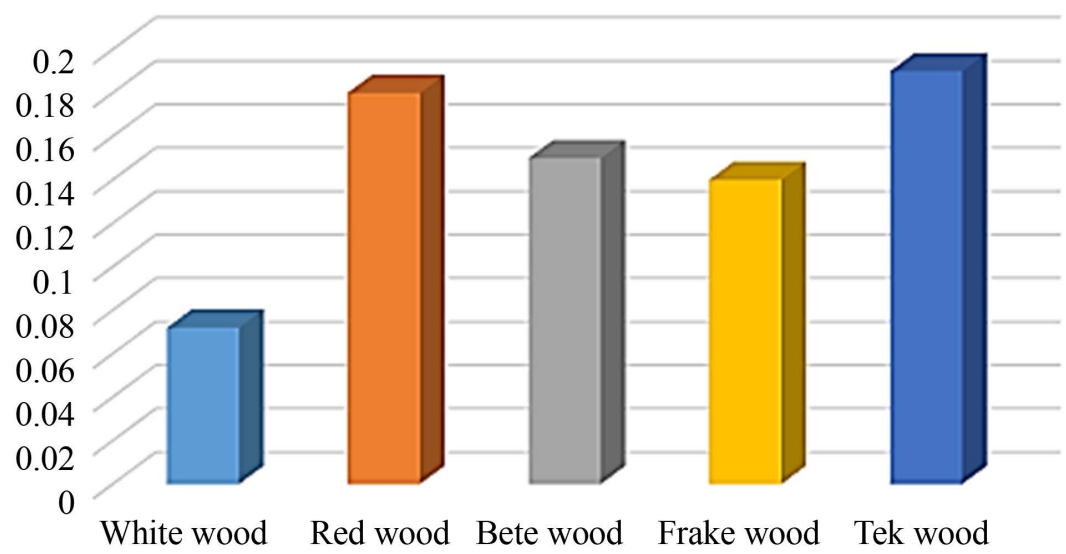

Figure 4. Test results for thermal conductivity of wood. 


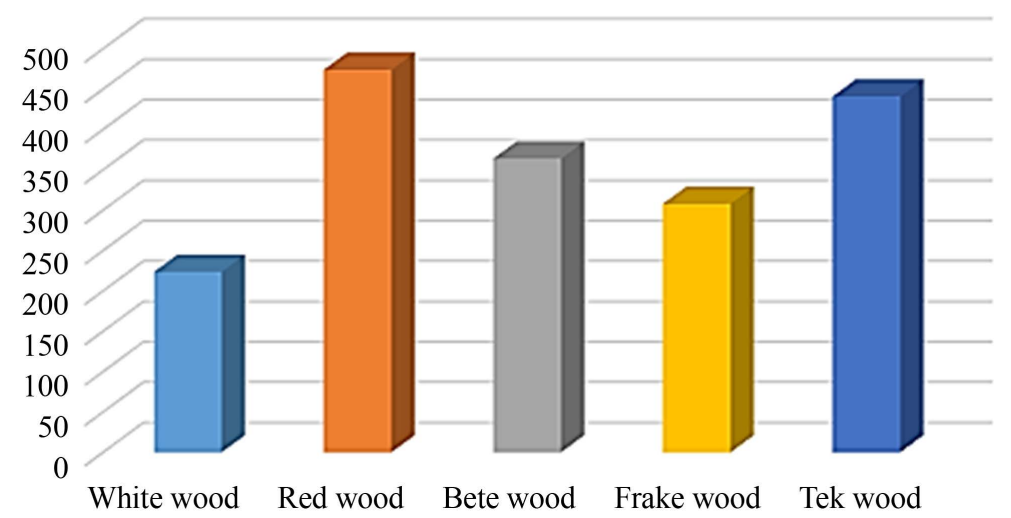

Figure 5. Test results for thermal effusivity of wood.

\subsubsection{Thermal Diffusivity}

The lower the thermal diffusivity value, the longer it will take for the heat front to cross. The order of magnitude of the thermal diffusivity given in the literature is $1 \times 10^{-7}$ to $3 \times 10^{-7} \mathrm{~m}^{2} / \mathrm{s}$ [12]. Our tests for the determination of the thermal diffusivity of wood allowed us to obtain the results in Figure 6.

We observe that tek wood has the highest diffusivity, which means that it is wood that reacts as quickly as possible to the change in temperature. White and fresh wood have the same values of thermal diffusivity as red and bete wood which have the lowest thermal diffusivities.

\subsection{Influence of Density on Combustion Parameters}

At the material scale, the PCFC (Pyrolysis Combustion Flow Calorimetry) makes it possible to quantify the heat flow rate (HRR) of the material (as a function of the pyrolysis temperature and the combustion temperature) with only a few milligrams of material. This data is an important parameter in the understanding of the development of a fire. Friederich assumes that at CCFCs, only gas-phase mechanisms are observed, [13]. Two other combustion parameters are also followed in this paragraph, namely the residue after combustion and the enthalpy which expresses the amount of heat involved in a thermomechanical transformation.

Thus, the microcalorimeter combustion analysis of the different types of wood allowed us to obtain the results recorded in Table 2.

Following these results, we also analyzed the influence of the density of each wood on the measured parameters and the results are presented in Figures 7-11.

The results show that tek and bete woods have the same charcoal content (20\%), frake and white woods (about 18\%) with different densities. Also, there is not a significant difference in terms of coal except red wood which has a low content (14\%).

We find that red wood has a low coaling this may explain the fact that it has a heat flow, a maximum heat flow as well as a complete combustion energy which 


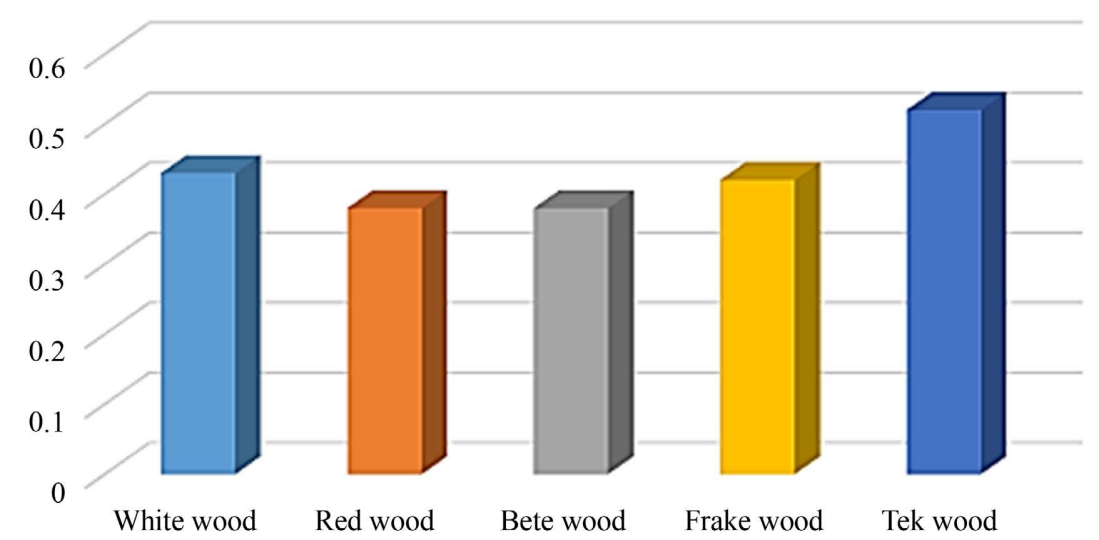

Figure 6. Test results for thermal diffusivity of wood.

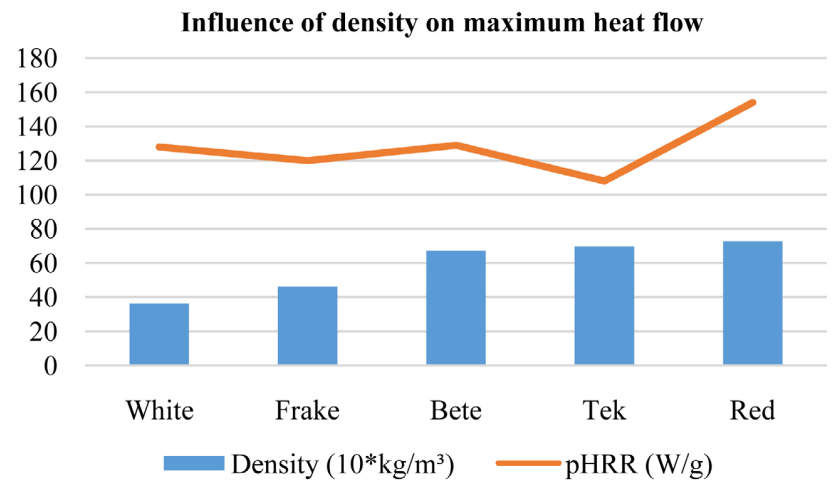

Figure 7. Influence of density on maximum heat flow.

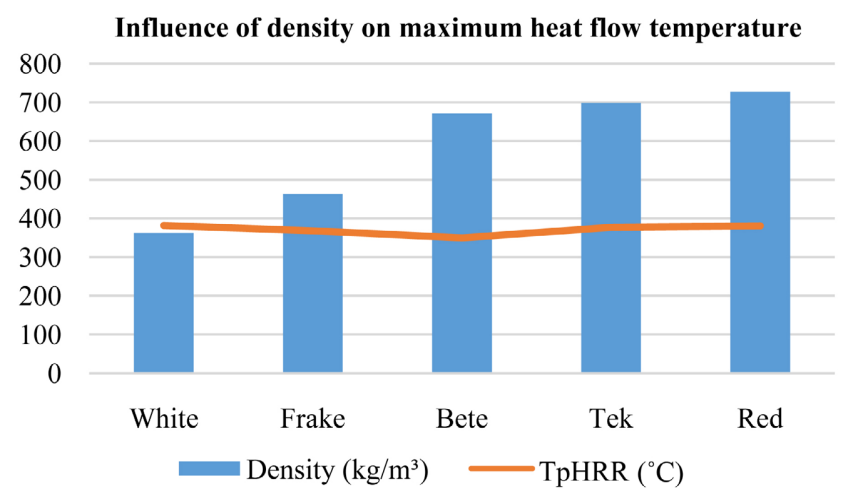

Figure 8. Influence of density on maximum heat flow temperature.

is a little higher than other types of wood. Low coal mining is correlated with greater energy released.

The maximum heat flow rates and maximum flow temperature of our woods follow the same order of magnitude. These values obtained are consistent with those obtained by Sonnier and al., who, in their research work, have established a database of the fire behaviour of several woods [14]. Their results teach us that all the woods are in the same range in terms of microscale fire behaviour. 
Influence of density on total heat released

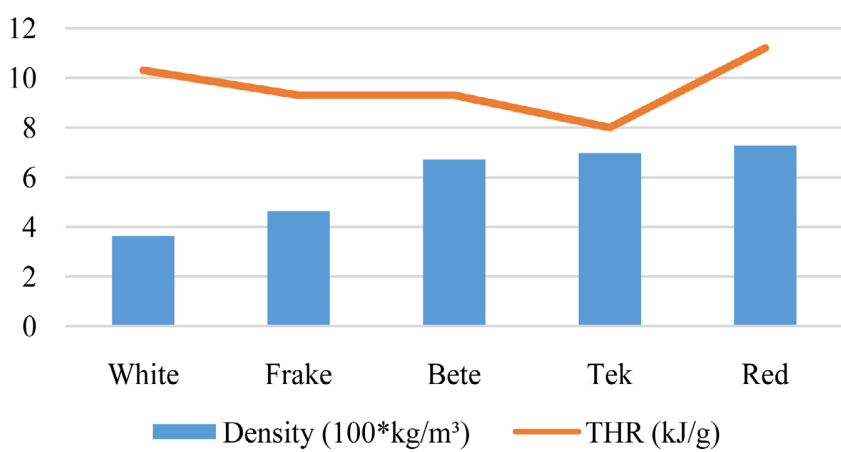

Figure 9. Influence of density on total heat released.

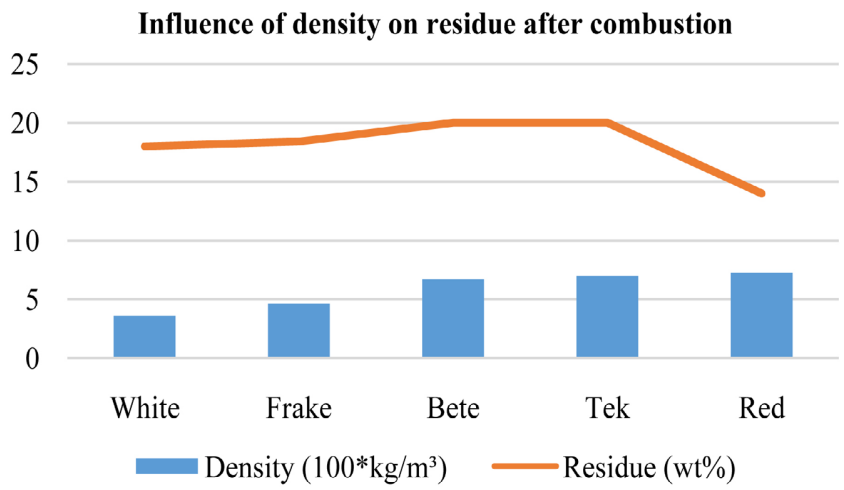

Figure 10. Influence of density on residue after combustion.

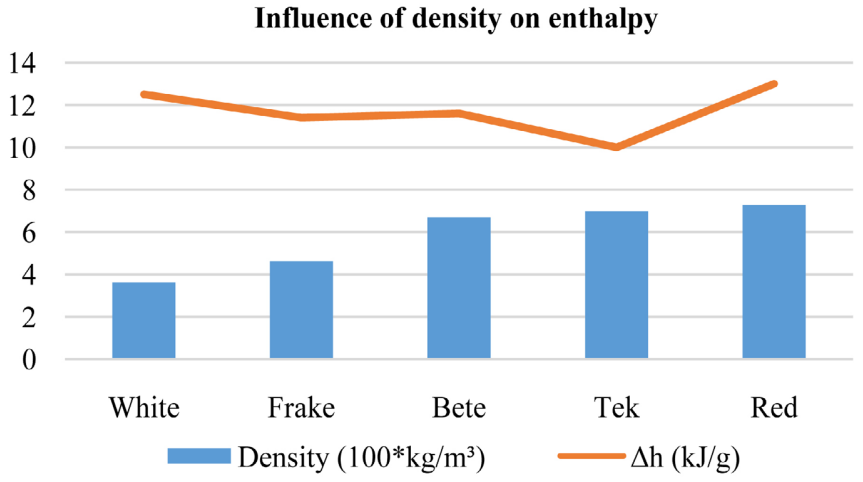

Figure 11. Influence of density on enthalpy.

Table 2. Main experimental data of wood studied at PCFC.

\begin{tabular}{ccccccc}
\hline $\begin{array}{c}\text { Types } \\
\text { woods }\end{array}$ & $\begin{array}{c}\text { Density } \\
\left(\mathrm{kg} / \mathrm{m}^{3}\right)\end{array}$ & $\begin{array}{c}\text { pHRR } \\
(\mathrm{W} / \mathrm{g})\end{array}$ & $\begin{array}{c}\text { TpHRR } \\
\left({ }^{\circ} \mathrm{C}\right)\end{array}$ & $\begin{array}{c}\text { THR } \\
(\mathrm{kJ} / \mathrm{g})\end{array}$ & $\begin{array}{c}\text { Residue } \\
(\mathrm{wt} \%)\end{array}$ & $\begin{array}{c}\Delta \mathrm{h} \\
(\mathrm{kJ} / \mathrm{g})\end{array}$ \\
\hline White & 362 & 128 & 382 & 10.3 & 18 & 12.5 \\
Frake & 463 & 120 & 368 & 9.3 & 18.4 & 11.4 \\
Bete & 671 & 129 & 350 & 9.3 & 20 & 11.6 \\
Tek & 698 & 108 & 377 & 8 & 20 & 10 \\
Red & 727 & 154 & 381 & 11.2 & 14 & 13 \\
\hline
\end{tabular}


We note that, despite the difference in the densities of different types of wood studied, the values obtained are almost similar from the point of view of heat release except for red wood whose values are a bit higher than the other 4 types of wood. The fire behaviour of these materials is very little variable on a material scale. We can conclude that at this level there is no major difference for our different types of wood so no influence of density on the material scale.

\subsection{Complete Combustion Temperatures from Combustion Efficiency " $X$ "}

The combustion efficiency is the ratio of the total heat rate released at a temperature $T$ to the total heat rate released at $900^{\circ} \mathrm{C}$. The combustion efficiency is obtained from the following equation:

$$
X=\frac{\operatorname{THR}(T)}{\operatorname{THR}\left(900^{\circ} \mathrm{C}\right)}
$$

where $T$ is the combustion temperature considered.

Figure 12(a) and Figure 12(b) and Table 3 show the evolution of the combustion efficiency as a function of the combustion temperature for the different woods.

At the level of the table, the results obtained allow us to note that the frake and tek woods show the same trend from $600^{\circ} \mathrm{C}$ to $900^{\circ} \mathrm{C}$ with almost similar combustion efficiencies. With regard to bete wood, its combustion efficiency at $600^{\circ} \mathrm{C}(0.48)$ seems to be the lowest, so we find that from $625^{\circ} \mathrm{C}$ it has the highest efficiency (0.71). Red and white woods have the same combustion efficiencies from $600^{\circ} \mathrm{C}$ to $625^{\circ} \mathrm{C}$, from $650^{\circ} \mathrm{C}$ to $725^{\circ} \mathrm{C}$ that of red wood seems to be much higher. Considering that from combustion efficiency $X$ greater than or equal to 0.9 we begin the complete combustion phase then we can affirm that for white and tek wood and the complete combustion begins at $700^{\circ} \mathrm{C}$. By this same method of analysis, we come to the conclusion that the frake, bete and red woods tend towards a complete combustion at $675^{\circ} \mathrm{C}$.

However, the combustion efficiency curve (Figure $12(\mathrm{a})$ ) is flat at $725^{\circ} \mathrm{C}$ for wood, and therefore close to 1 . It is therefore possible to conclude that overall combustion is complete at this temperature for the types of wood analyzed.

Finally, Figure 12 (b) allows us to observe that at $675^{\circ} \mathrm{C}$ the bete and frake woods have the best combustion yields, to a lesser extent than the red and tek woods.

\subsection{Comparison of the Activation Energies of the Different Types of Wood}

This is the amount of energy that must be brought to a system to initiate a chemical reaction from the moment when one wants to start a process. One often has to face an energy barrier (i.e. bring a minimum of energy for the start-up). In the case of fire safety this parameter also remains crucial to understanding and explaining what happens during fires in habitats and also to simulating the spread/evolution of fires during a fire condition in a dwelling house. 
Table 3. Combustion efficiency of the different types of wood studied.

\begin{tabular}{|c|c|c|c|}
\hline \multicolumn{4}{|c|}{ White wood } \\
\hline (THR) $\mathrm{T}$ & (THR) 900 & $\mathrm{X}$ & Temperature $\left({ }^{\circ} \mathrm{C}\right)$ \\
\hline 6 & 10.3 & 0.5 & 600 \\
\hline 6.3 & 10.3 & 0.6 & 625 \\
\hline 8.1 & 10.3 & 0.7 & 650 \\
\hline 8.9 & 10.3 & 0.8 & 675 \\
\hline 9.3 & 10.3 & 0.9 & 700 \\
\hline 9.7 & 10.3 & 0.9 & 725 \\
\hline 10.3 & 10.3 & 1 & 900 \\
\hline \multicolumn{4}{|c|}{ Tek wood } \\
\hline (THR) $\mathrm{T}$ & (THR) 900 & $\mathrm{X}$ & Temperature $\left({ }^{\circ} \mathrm{C}\right)$ \\
\hline 4.2 & 8 & 0.5 & 600 \\
\hline 5.3 & 8 & 0.6 & 625 \\
\hline 7 & 8 & 0.8 & 650 \\
\hline 7.15 & 8 & 0.8 & 675 \\
\hline 7.3 & 8 & 0.9 & 700 \\
\hline 7.9 & 8 & 0.9 & 725 \\
\hline 8 & 8 & 1 & 900 \\
\hline \multicolumn{4}{|c|}{ Frake wood } \\
\hline (THR) $\mathrm{T}$ & (THR) 900 & $\mathbf{X}$ & Temperature $\left({ }^{\circ} \mathrm{C}\right)$ \\
\hline 4.9 & 9.3 & 0.5 & 600 \\
\hline 6.2 & 9.3 & 0.6 & 625 \\
\hline 7.2 & 9.3 & 0.7 & 650 \\
\hline 8.9 & 9.3 & 0.9 & 675 \\
\hline 9 & 9.3 & 0.9 & 700 \\
\hline 9.2 & 9.3 & 0.9 & 725 \\
\hline 9.3 & 9.3 & 1 & 900 \\
\hline \multicolumn{4}{|c|}{ Bete wood } \\
\hline (THR) $\mathrm{T}$ & (THR) 900 & $\mathrm{X}$ & Temperature $\left({ }^{\circ} \mathrm{C}\right)$ \\
\hline 4.5 & 9.3 & 0.4 & 600 \\
\hline 6.7 & 9.3 & 0.7 & 625 \\
\hline 7.6 & 9.3 & 0.8 & 650 \\
\hline 9 & 9.3 & 0.9 & 675 \\
\hline 9.1 & 9.3 & 0.9 & 700 \\
\hline 9.2 & 9.3 & 0.9 & 725 \\
\hline 9.3 & 9.3 & 1 & 900 \\
\hline
\end{tabular}




\section{Continued}

\begin{tabular}{cccc}
\hline \multicolumn{3}{c}{ Red wood } \\
\hline$($ THR) T & (THR) 900 & $\mathrm{X}$ & Temperature $\left({ }^{\circ} \mathrm{C}\right)$ \\
\hline 6.6 & 11.2 & 0.5 & 600 \\
7.1 & 11.2 & 0.6 & 625 \\
9.8 & 11.2 & 0.8 & 650 \\
10.1 & 11.2 & 0.9 & 675 \\
10.7 & 11.2 & 0.9 & 700 \\
11.1 & 11.2 & 0.9 & 725 \\
11.2 & 11.2 & 1 & 900 \\
\hline
\end{tabular}

Combustion efficiency as function as combustion temperature

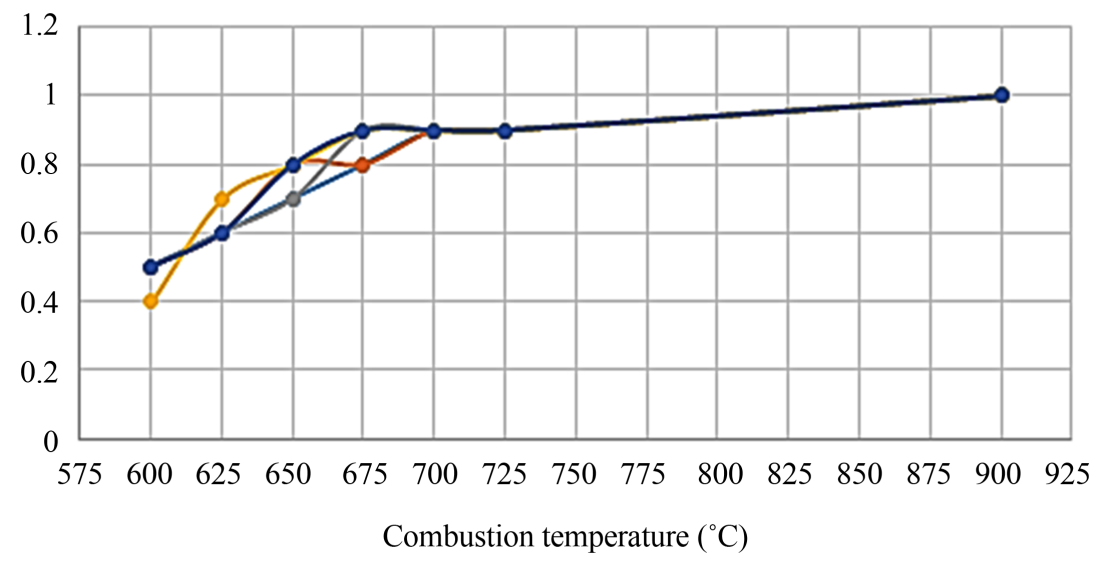

$\rightarrow$ White wood $\rightarrow$ Tek wood $\rightarrow$ Frake wood $\rightarrow$ Bete wood $\rightarrow$ Red wood

(a)

Efficiency of combustion

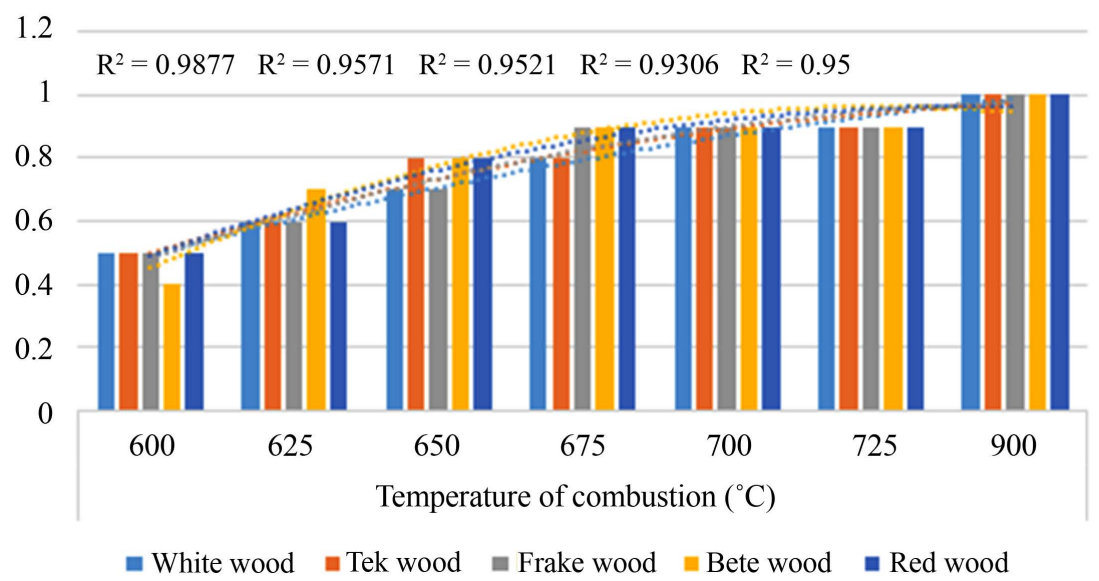

(b)

Figure 12. (a) Combustion efficiency as a function of wood combustion temperature; (b) Combustion efficiency as a function of wood combustion temperature. 
Generally, its value is between 20 and $200 \mathrm{~kJ} \cdot \mathrm{mol}^{-1}$ for combustion activation. To obtain the activation energy " $E a$ " of combustion we used the following equation:

$$
\ln [-\ln (1-X(T))]=\ln (\beta \cdot \tau)-\frac{E a}{R T C} \quad[14]
$$

$E a$ is the activation energy;

$X$ is the combustion efficiency;

$\beta$ is the pre-exponential factor or frequency factor taking into account the frequency of collisions and steric effects, $\tau$ is the burning time;

$R$ is the constant of perfect gases;

$T=T c$ is the combustion temperature (isothermal system).

The activation energy $E a$ is calculated from the slope of the curve of $\ln (\beta \cdot \tau)-\frac{E a}{R T C}$ as a function of $1 / T c[6]$. Figures 13-17 show the slopes obtained for the types of wood analyzed. Figure 18, on the other hand, gives us an overview of the summary of the activation energies obtained.

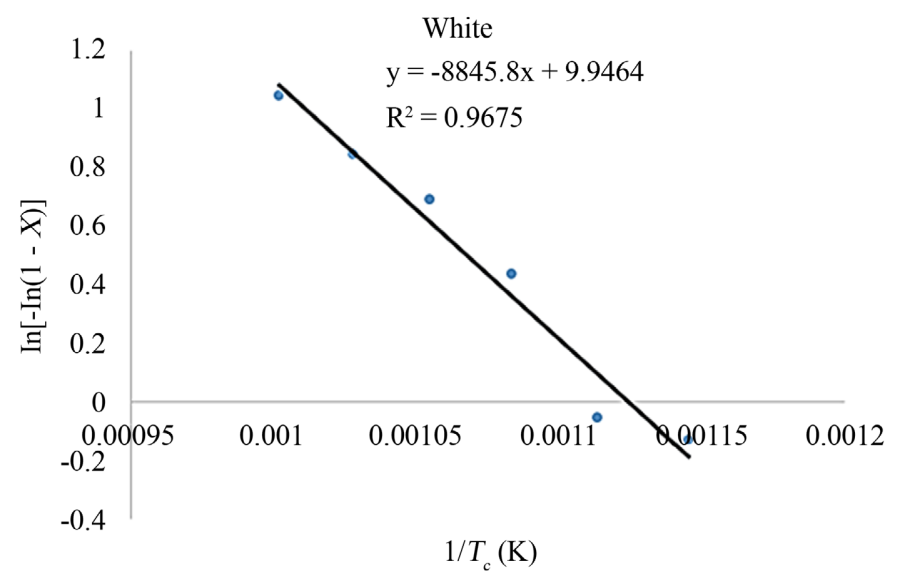

Figure 13. White wood activation energy.

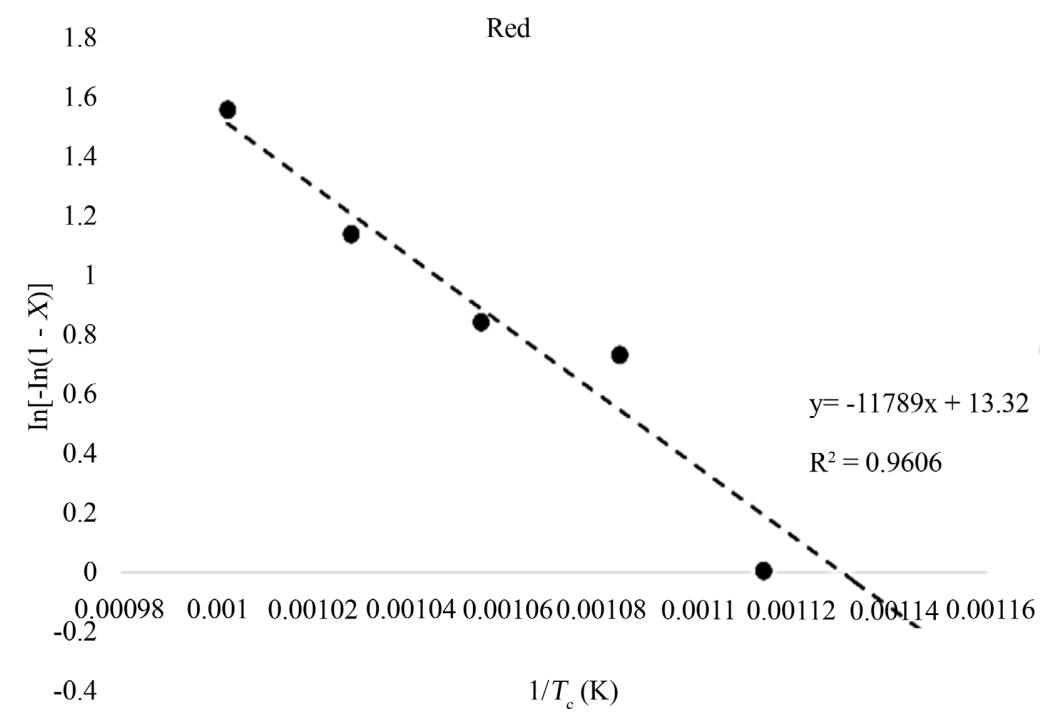

Figure 14. Red wood activation energy. 


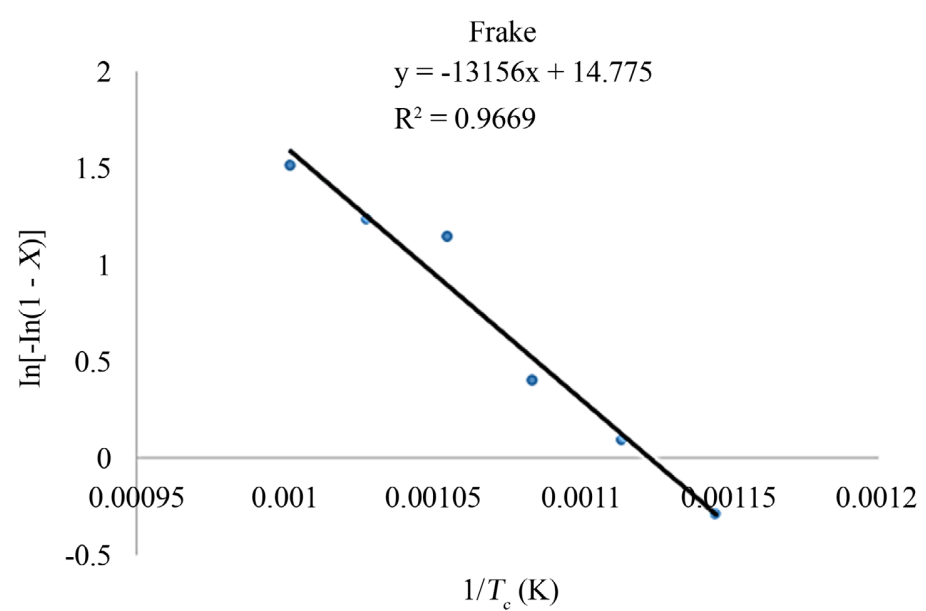

Figure 15. Frake wood activation energy.

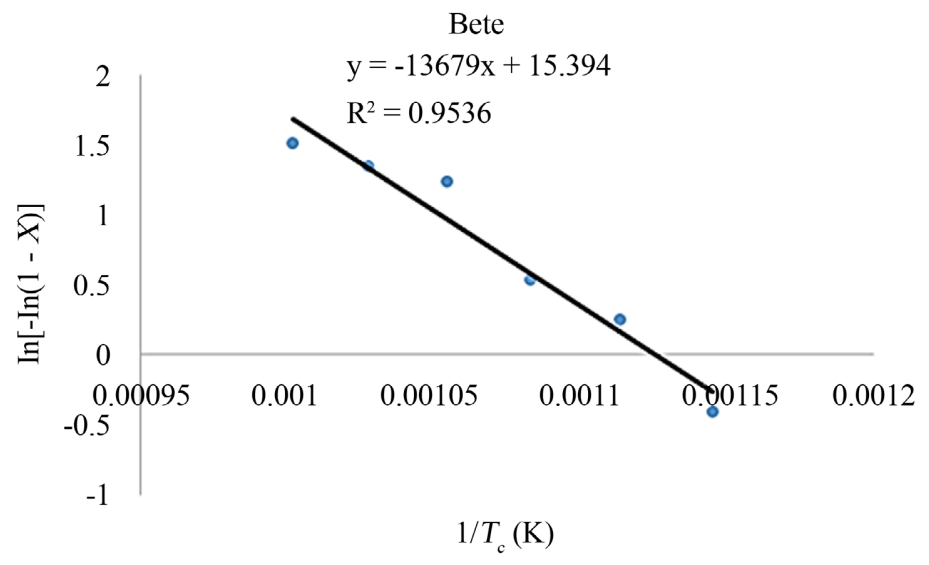

Figure 16. Bete wood activation energy.

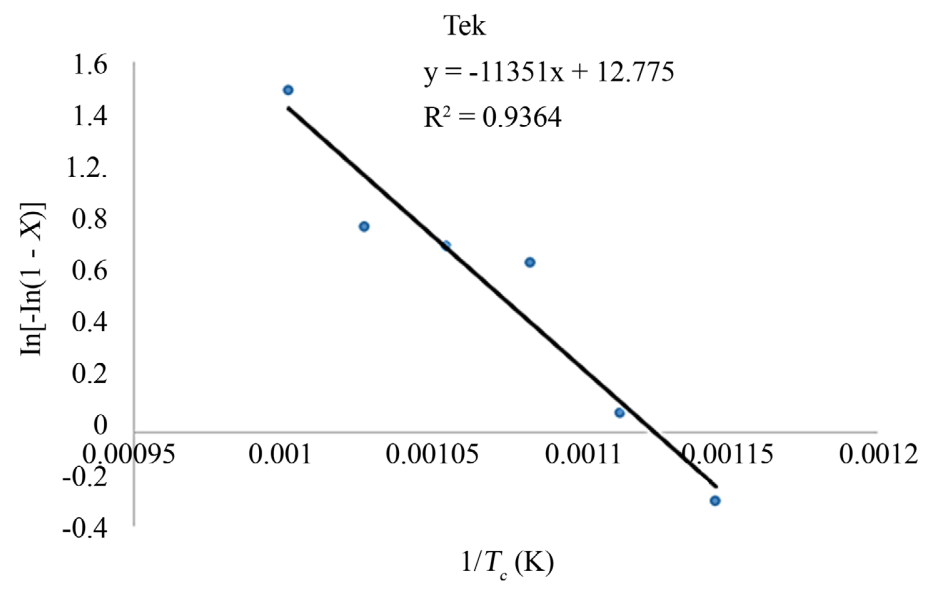

Figure 17. Tek wood activation energy.

From these results, we note that these values are relatively dispersed from one wood to another. Bete wood has the highest activation energy and white wood the lowest. Yet, the activation energies of the red, frake and tek woods are very close to one another. 


\section{$\operatorname{Ea}(\mathrm{Kj} / \mathrm{mol} \cdot \mathrm{K})$}

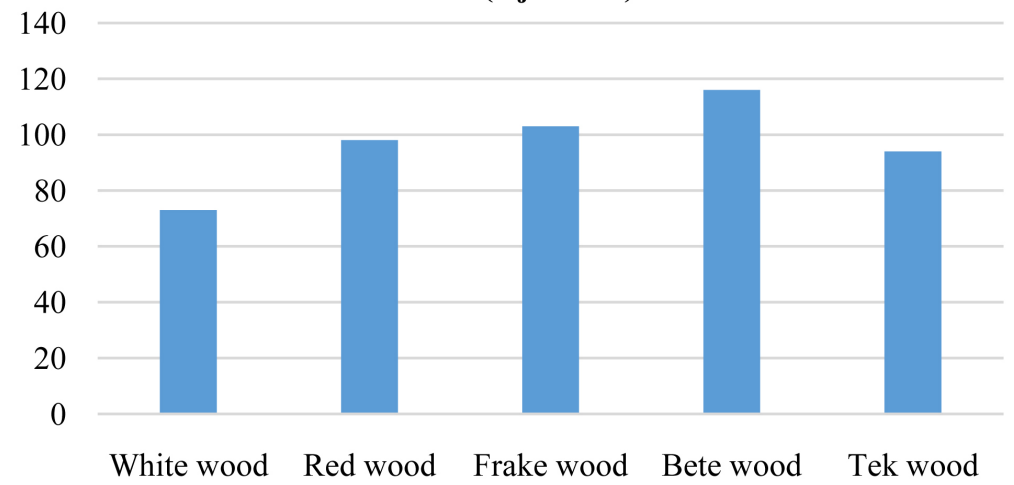

Figure 18. Summary of wood activation energies.

\section{Conclusion}

The objective of this work was to characterize the thermophysical parameters of the wood that we find within the habitat in order to better understand their behaviour in fires and to strengthen the database of materials involved in fires in domestic habitats. Our study shows that the mechanical and physical properties of wood are dependent on a large number of factors that can be more or less influential and more or less easy to quantify. Bete, frake red, white and tek woods, respectively, show better results in terms of resistance and in terms of conductivity, effusivity and diffusivity. The microcalorimeter tests allowed us to obtain results that show that there is not a major difference in the elemental composition but morphologically, white wood seems to be less rigid, less dense and produces the least heat when it burns.

\section{Conflicts of Interest}

The authors declare no conflicts of interest regarding the publication of this paper.

\section{References}

[1] Di Blasi, C. (1993) Modeling and Simulation of Combustion Processes of Charring and Non-Charring Solid Fuels. Progress in Energy and Combustion Science, 19, 71-104. https://doi.org/10.1016/0360-1285(93)90022-7

[2] Staggs, J.E.J. (2002) Estimating the Thermal Conductivity of Chars and Porous Residues Using Thermal Resistor Networks. Fire Safety Journal, 37, 107-119. https://doi.org/10.1016/S0379-7112(01)00035-2

[3] Hao, C.T. (1992) Experimental Data on Wood Materials. In: Babrauskas, V. and Grayson, S.J., Eds., Heat Release in Fires, Elsevier Applied Science, London, 357-372.

[4] Marquis, D. (2007) Tenue au feu des composites.

[5] Sallenave, P. (1964) Propriétés physiques et mécaniques des bois tropicaux. Publication No. 23 du Centre Technique Forestier Tropical, Premier supplément; Centre Technique Forestier Tropical; 45 bis, Avenue de la Belle-Gabrielle nogent-sur-marne (Seine), France.

[6] Lyon, R.E. and Walters, R.N. (2004) Pyrolysis Combustion Flow Calorimetry. Jour- 
nal of Analytical and Applied Pyrolysis, 71, 27-46.

https://doi.org/10.1016/S0165-2370(03)00096-2

[7] Susott, R.A. (1980) Thermal Behavior of Conifer Needle Extractives. Forest Science, 26, 347-360. https://doi.org/10.1093/forestscience/26.3.347

[8] Schartel, B., Pawlowski, K.H. and Lyon, R.E. (2007) Pyrolysis-Combustion Flow Calorimeter: A Tool to Assess Flame Retarded PC/ABS Materials. Thermochimica Acta, 462, 1-14. https://doi.org/10.1016/j.tca.2007.05.021

[9] Le Frious, F. (2010) Les propriétés thermiques des matériaux et les références métrologiques.

[10] Gidik, H. (2015) Réalisation d'un fluxmètre thermique à gradient tangentiel de température à paroi auxiliaire textile intégrant des fils thermoélectriques: Application à la mesure des transferts thermiques et hydriques.

[11] Yala-Aithammouda, M. (2007) Étude et réalisation de microcapteurs de flux thermique en technologie silicium.

[12] Thompson, E.V. (1999) Polymer Data Handbook. Journal of the American Chemical Society, 131, 1012.

[13] Friederich, B. (2011) Développement de nouveaux systèmes retardateurs de flammes à base de nano composites plus respectueux de l'environnement. Thèse de doctorat, Université Paul Verlaine de Metz, Metz.

[14] Sonnier, R., Otazaghine, B., Iftene, F., Negrell, C., David, G. and Howell, B.A. (2016) Predicting the Flammability of Polymers from Their Chemical Structure: An Improved Model Based on Group Contributions. Polymer, 86, 42-55.

https://doi.org/10.1016/j.polymer.2016.01.046 